\title{
Sero-epidemiological assessment of Chlamydia trachomatis infection and sub-fertility in Samoan women
}

\author{
S. Menon ${ }^{1 \dagger}$, S. H. Stansfield ${ }^{1 \dagger}$, M. Walsh ${ }^{2 \dagger}$, E. Hope ${ }^{3 \dagger}$, L. Isaia ${ }^{4}$, A. A. Righarts ${ }^{2}$, T. Niupulusu' ${ }^{5}$, S. V. A. Temese ${ }^{6}$,

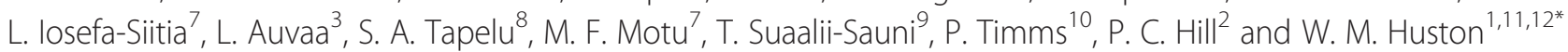

\begin{abstract}
Background: In our recent village-based cross-sectional study, the prevalence of nucleic acid amplification technique (NAAT) diagnosed Chlamydia trachomatis (CT) in sexually active Samoan women was very high (36 \%), and test positivity was associated with sub-fertility. We conducted a serological and epidemiological analysis in these participants to identify if serological data can provide further insight into the potential contribution of $\mathrm{CT}$ to sub-fertility in this population.

Methods: Serological prediction of CT associated sub-fertility was conducted using a series of commercial tests. The correlation between fertility or sub-fertility, behavioral factors, and serologically predicted CT associated subfertility was determined.

Results: A positive antibody reaction against the Chlamydia Major Outer Membrane Protein (MOMP) was significantly associated with sub-fertility, with $50 \%$ of infertile women being positive. Serum IgG and IgA antibodies against MOMP correlated with current infection measured by urine NAAT, suggesting longer term infections are common in this population. Chlamydia pneumoniae antibodies were frequently detected in this population (84 \%), and unexpectedly, were significantly associated with sub-fertility.

Conclusions: The high prevalence of chlamydial infection and of positive chlamydial sub-fertility results suggests that $C T$ is an important and frequent contributory factor to sub-fertility in this population.
\end{abstract}

Keywords: Chlamydia, Pacific islands, samoa, female sub-fertility, diagnosis, serology

\section{Background}

Chlamydia trachomatis (CT) is the most common bacterial sexually transmitted infection (STI) in the world. The infection can result in the development of serious sequelae such as pelvic inflammatory disease (PID), ectopic pregnancy and tubal factor infertility (TFI) in women. The reported prevalence of CT infection is in the range $1.4-8.7 \%$ when the general population in high income countries is screened [1-3]. The prevalence of CT infection in Samoa was previously estimated by

\footnotetext{
* Correspondence: Wilhelmina.Huston@uts.edu.au

${ }^{\dagger}$ Equal contributors

${ }^{1}$ Institute of Health and Biomedical Innovation, Queensland University of

Technology, Brisbane, Australia

${ }^{11}$ School of Life Sciences, Faculty of Science, University of Technology

Sydney, Broadway, Sydney, NSW, Australia

Full list of author information is available at the end of the article
}

Sullivan et al. [4] to be $30.9 \%$ based on antenatal screening. Similarly, in women who attended antenatal clinics between 2004 and 2005 in the Pacific Islands (Fiji, Kiribati, Samoa, Solomon Islands, Tonga, and Vanuatu), CT prevalence was $26.1 \%$ in women under 25 years old, and $11.9 \%$ in women over 25 [5].

The proportion of infertility attributable to CT in the Samoan population is not known. Such infertility results from tissue damage to the fallopian tubes (tubal factor infertility, TFI) that remains after the active infection is cleared, meaning that diagnosis using nucleic acid amplification tests (NAAT) is not necessarily suitable. There are numerous serological or chlamydia antibody tests (CAT) that have been developed to diagnose CT infertility, that have been validated on cohorts of women with evidence of tubal damage detected by hysterosalpingography or 
laparoscopy [6-11]. In a meta-analysis of published evaluations of various assays, Broeze and co-workers identified that micro immune-fluorescence (MIF) was the most sensitive, but relatively low in specificity [6]. In the same study the MEDAC and ANIlabsystems enzyme linked immunosorbant assays (ELISA) appeared to most specific, although less sensitive than MIF, to diagnose women with uni or bi-lateral tubal damage detected by surgical or sonographic technologies [6]. However, a proportion of women with infertility and who are serologically positive by CAT have no detectable tubal blockage but still require IVF (in vitro fertilization) to conceive, and this could be at least partially due to tubal damage not detectable by the current surgical or sonographic methods [7, 12-14]. In lower and middle income countries (LMIC) studies generally report higher prevalence of $\mathrm{CT}$ in infertile or subfertile women (39-55\%), although the prevalence of CT infection in fertile women is also generally high [15-17].

We recently reported a high prevalence $(36.0 \%$ by NAAT) of CT in Samoan women using communitybased screening and survey of sexually active women aged 18-29 years having unprotected sex, and current infection was associated with women who were defined as being sub-fertile $[14,18]$. Here, we conducted a serological study to evaluate the prevalence of $\mathrm{CT}$ associated sub-fertility in these same women.

\section{Methods}

The study design and sampling protocol has been previously reported $[15,18]$. Women $(n=239)$ were recruited into a cross-sectional study on CT and sub-fertility from the Pacific nation of Samoa during 2011. Participant inclusion criteria were age between 18 and 29 years, living in the village for at least a year and being sexually active without using any forms of contraception (including condoms, birth control pills, or other forms of contraception) for at least a year. Women were excluded if they had a medical condition, or had undergone a procedure that made it impossible to become pregnant. Participants provided informed written consent, completed an interviewer-led questionnaire and provided biological samples. The nurse who conducted the interview asked the sexual behavioral questions using socially acceptable language and used a two step approach to gauge sexual behavior (as previously described) [18]. The questionnaire responses were used to assign women to 'sub-fertile' (or otherwise 'fertile'). Sub-fertility was defined as at least 12 months of unprotected intercourse without conceiving a pregnancy [18]. The NAAT results have been previously analysed and presented [18], all participants provided a urine specimen that was analysed for $\mathrm{CT}$ infection status using the BD ProbeTec ET assay in accordance with the manufacturer's instructions and using positive and negative controls (BD Biosciences, USA) [18].

The participant sera were tested for CT antibodies using the following commercial ELISAs: CT-IgG ELISAplus MEDAC (peptides from the MOMP protein, referred to as MEDAC MOMP, used to diagnose past or current infection), cHSP60-IgG ELISA MEDAC (cSHP60 protein), ANIlabsystems CT IgG (peptides from MOMP, marketed to diagnose CT infertility), CT IgA ELISA MEDAC (used to diagnose current CT infection), Chlamydia pneumoniae (CP)-IgG-ELISA MEDAC (used to diagnose current $\mathrm{CP}$ infection) (summarized in Table 1). The assay positive or negative results in accordance with the manufacturer's instructions were used for this study (positive, negative, unequivocal (excluded), invalid (excluded)). Titres were not included in this study as they are not part of these commercial tests. All sera were tested with all assays, however, any that were unequivocal or invalid more than once were excluded from the data for that assay and any participants that did not have a complete dataset and valid test result in every assay were completely excluded from the analysis in Table 2 and Fig. 2. The serological testing of CT associated subfertility is difficult because the gold standard (MIF) has low specificity leading to high false positives (although it had the highest accuracy using area under the curve), but is reported to be highly subjective and labor intensive [6]. Therefore we chose to test the population using ELISA as we prioritised highest specificity in order to

Table 1 Commercial serological assays and previously reported sensitivity and specificity

\begin{tabular}{|c|c|c|c|c|c|c|}
\hline Assay name & Antigen & Study reference name & Sensitivity & Specificity & Detected group & Ref \\
\hline MEDACCT-IgG ELISA-plus MEDAC & MOMP & MEDAC MOMP & $55 \%$ & $87 \%$ & Women with infertility $(n=315)$ & {$[7]$} \\
\hline cHSP60-IgG ELISA MEDAC & CHSP60 & MEDAC cHSP60 & $69 \%$ & $93 \%$ & Women with TFI $(n=70)$ & [22] \\
\hline $\begin{array}{l}\text { MEDAC IgG CT pELISA } \\
\text { and CHSP60 IgG ELISA }\end{array}$ & $\begin{array}{l}\text { Combination of } \\
\text { both assays }\end{array}$ & MEDAC Infertile & & & & [22] \\
\hline ANIlabsystems CT IgG & MOMP peptides & ANIlab & $91 \%$ & $84 \%$ & $\begin{array}{l}\text { CT NAAT diagnosed infection and } \\
\text { infertility }(n=303)\end{array}$ & [16] \\
\hline $\mathrm{CT}$ IgA ELISA MEDAC & MOMP peptides & MEDAC IgA & & & NAAT diagnosed current infection & [23] \\
\hline C. pneumoniae-lgG-ELISA MEDAC & MOMP peptides & MEDAC Cpn & $91.3 \%$ & $93.3 \%$ & $\begin{array}{l}\text { Current pneumonia and MIF positive } \\
\text { status for C. pneumoniae }\end{array}$ & [24] \\
\hline
\end{tabular}


Table 2 Participant data included/excluded in the Table 3

\begin{tabular}{|c|c|c|c|c|}
\hline Variable & Included, n & Excluded, $\mathrm{n}$ & OR (95 \% C.I.) & $P$ value for $O R$ \\
\hline \multicolumn{5}{|l|}{$\overline{\text { Age }}$} \\
\hline $18-24$ & 97 & 48 & 1 & \\
\hline $25-29$ & 64 & 29 & $1.11(0.63-1.94)$ & 0.720 \\
\hline \multicolumn{5}{|l|}{ Smoking } \\
\hline Never & 129 & 59 & 1 & \\
\hline $\begin{array}{l}\text { Ex-smoker/ } \\
\text { current }\end{array}$ & 33 & 18 & $0.84(0.44-1.61)$ & 0.600 \\
\hline \multicolumn{5}{|l|}{ Fertility status } \\
\hline Sub-fertile & 59 & 28 & 1 & \\
\hline Fertile & 103 & 49 & $1.00(0.57-1.75)$ & 0.990 \\
\hline
\end{tabular}

Comparison of Age, smoking and fertility status for participants included or excluded in the study. Participants excluded had no statistical difference in age, smoking or fertility status $(P>0.05)$

indicate the amount of $\mathrm{CT}$ associated sub-fertility in Samoa, and a format that could enable us to compare several tests in a timely manner. We selected multiple ELISAs to compare the different IgG responses and we also included IgA to indicate how many of the infections were recent. Finally, we included a Chlamydia pneumoniae ELISA to enable comparison of the sero-prevalence of a related and very common pathogen.

All statistical analyses were conducted in R statistical environment (3.0.3) using the 'EpiR (0.9-57) and 'metafor' package (1.9-2) for calculation and presentation (forest plots) of odds ratios (OR). All analyses were conducted to measure the association of assay results with sub-fertility. OR and $95 \%$ confidence intervals (CI) were calculated with restricted maximum likelihood estimates of error.

\section{Results}

\section{Antibody test results for $\mathrm{CT}$ associated sub-fertility}

Two hundred thirty-nine women meeting the inclusion and exclusion criteria participated in the study; 90 were defined as being sub-fertile and 149 were defined as fertile with a history of having had a pregnancy. The association of CT with sub-fertility was analysed using each of the commercial serological assays. As shown in Fig. 1a, women who were sub-fertile were significantly more likely to have a positive serological reaction in the MEDAC MOMP assay ( $\mathrm{p}=0.045) .42$ out of 82 sub-fertile women were positive in the MEDAC MOMP assay, whereas 52 out of a total of 139 fertile women were positive. It is important to note that 34 sub-fertile women have been excluded for this assay from Fig. 1a because they had unequivocal results. One of the most common immunological reactions that was associated with infertility in previous studies $[9,12]$, an antibody response to cHSP60, was not significantly associated with sub-fertility: the seroprevalence of antibodies to cHSP60 did not differ based on fertility with $57 \%$ of both infertile and fertile women being positive (44 out of 76 sub-fertile women were positive and 73 out of 129 fertile women were positive). The

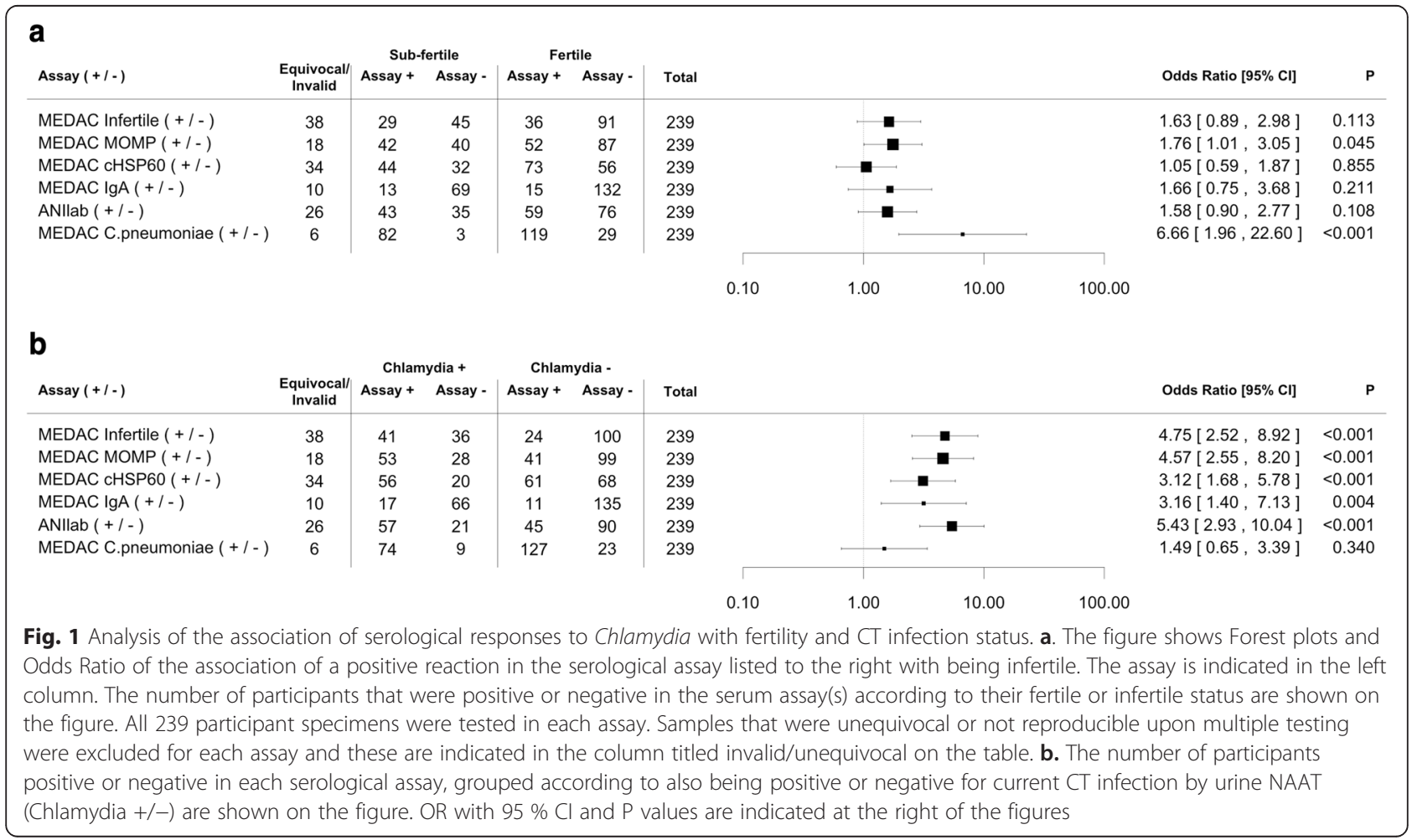


MEDAC Infertile assay, which is recommended by the manufacturer to be a positive reaction in both the MEDAC MOMP and MEDAC cHSP60 assays, was not significantly associated with sub-fertility in this study (in the infertile group 29 women were positive out of 74 total who had results in the assay, and 36 were positive out of a total of 127 women with reportable results in the fertile group).

The overall IgG sero-positivity to CT in this population was $43 \%$ according to the MEDAC MOMP results, and $50 \%$ according to the ANIlab assay. The numbers reported in Fig. 1 vary depending on the number of women that had consistent reportable results in the assay (i.e. we did not include unequivocal or invalid results, these are indicated to the left of the figure).

We included testing for a common respiratory pathogen (Chlamydia pneumoniae) to provide an indication of serological responses in our population tested. Women who were sub-fertile were significantly more likely to have a positive reaction in MEDAC CP assay $(\mathrm{p}<0.001)$ (Fig. 1a). The overall presence of sero-positivity to this pathogen (CP) was $86 \%$. A positive urine NAAT result did not correlate with a positive $\mathrm{CP}$ serological result, supporting that this assay is not likely to be detecting CT cross reactivity. Although, pairwise analysis did show that MEDAC MOMP positivity significantly correlated with MEDAC $\mathrm{CP}$ (chisel $\mathrm{p}=0.042$ ), meaning that women positive in MEDAC MOMP were more likely to be positive in MEDAC CP (OR 3.63 [95 \% CI: 0.92-21.11]).

We previously reported that the current infection by urine NAAT was $36 \%$ in this cohort [18], therefore, we evaluated if the serological results correlate with current infection status. Women who were NAAT positive were significantly more likely to be positive in the serological assays for $\mathrm{CT}$ by all of assays tested (Fig. 1b). The high association of IgG against MOMP and cHSP60 and current infection by urine NAAT in this cohort could imply these are longer term infections, consistent with the lack of STI screening and treatment programs in this country. A positive result in the MEDAC IgA significantly correlated with NAAT positive status (Fig. 1b) $(\mathrm{p}=0.004)$. This higher frequency of IgG (compared to IgA) correlating with NAAT diagnosed current infection further supports the possibility that in this population there are frequent repeat or longer term infections, given that IgA tends to be produced early and in primary infections.

In the evaluation of demographic factors in relation to subfertility and serological results, we only included data for participants that had a recordable result in every test and answered every demographic question $(n=162)$. The details of the participants excluded from this analysis are provided in Table 2, and there were no significant differences in the sub-fertility status or other factors in those excluded compared to those included. Age (older women were more likely to be fertile, $\mathrm{p}<$ 0.010), MEDAC MOMP ( $\mathrm{p}=0.040)$, NAAT positive for CT $(p=0.003)$ and MEDAC CP $(p=0.007)$ were all significant factors that associated with sub-fertility in this subset of participants (Table 3 ).

We used the same subset of specimens to assess test concordance. As shown in the Venn diagram (Fig. 2) there was often concordance between the serological

Table 3 Analysis of demographic factors and serological results that associate with sub-fertility

\begin{tabular}{|c|c|c|c|c|}
\hline Variable & $\begin{array}{l}\text { Sub-fertile, } \\
n\end{array}$ & $\begin{array}{l}\text { Fertile, } \\
\mathrm{n}^{\mathrm{a}}\end{array}$ & $\begin{array}{l}\text { OR } \\
(95 \% \text { C.I. })\end{array}$ & $\begin{array}{l}P \text { value } \\
\text { for OR }\end{array}$ \\
\hline \multicolumn{5}{|l|}{$\overline{\text { Age }}$} \\
\hline $18-24$ & 47 & 50 & 1 & \\
\hline $25-29$ & 12 & 53 & $0.24(0.11-0.51)$ & $<0.01$ \\
\hline \multicolumn{5}{|l|}{ BMl } \\
\hline Normal Weight & 12 & 21 & 1 & \\
\hline Overweight & 27 & 35 & $0.74(0.31-1.80)$ & 0.498 \\
\hline Obese & 20 & 47 & $0.74(0.31-1.80)$ & 0.512 \\
\hline \multicolumn{5}{|l|}{ Smoking } \\
\hline Never & 46 & 83 & 1 & \\
\hline Ex-smoker/current & 13 & 20 & $1.17(0.53-2.57)$ & 0.691 \\
\hline \multicolumn{5}{|l|}{ MEDAC Infertile } \\
\hline Negative & 34 & 72 & 1 & \\
\hline Positive & 25 & 31 & $1.71(0.88-3.33)$ & 0.115 \\
\hline \multicolumn{5}{|l|}{ MEDAC MOMP } \\
\hline Negative & 28 & 66 & 1 & \\
\hline Positive & 31 & 37 & $1.97(1.03-3.78)$ & 0.040 \\
\hline \multicolumn{5}{|l|}{ MEDAC CHSP60 } \\
\hline Negative & 25 & 41 & 1 & \\
\hline Positive & 34 & 62 & $0.9(0.47-1.72)$ & 0.749 \\
\hline \multicolumn{5}{|l|}{ MEDAC IgA } \\
\hline Negative & 49 & 89 & 1 & \\
\hline Positive & 10 & 14 & $1.3(0.55-3.14)$ & 0.563 \\
\hline \multicolumn{5}{|l|}{ ANIlab } \\
\hline Negative & 29 & 59 & 1 & \\
\hline Positive & 30 & 44 & $1.39(0.73-2.64)$ & 0.318 \\
\hline \multicolumn{5}{|l|}{ MEDAC CP } \\
\hline Negative & 2 & 22 & 1 & \\
\hline Positive & 57 & 81 & $7.74(1.75-34.21$ & 0.007 \\
\hline \multicolumn{5}{|l|}{ CT Infection (NAAT) } \\
\hline Negative & 28 & 73 & 1 & \\
\hline Positive & 31 & 30 & $2.69(1.39-5.24)$ & 0.003 \\
\hline
\end{tabular}

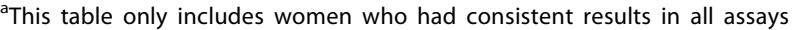
$(n=162), 59$ sub-fertile and 103 fertile women 


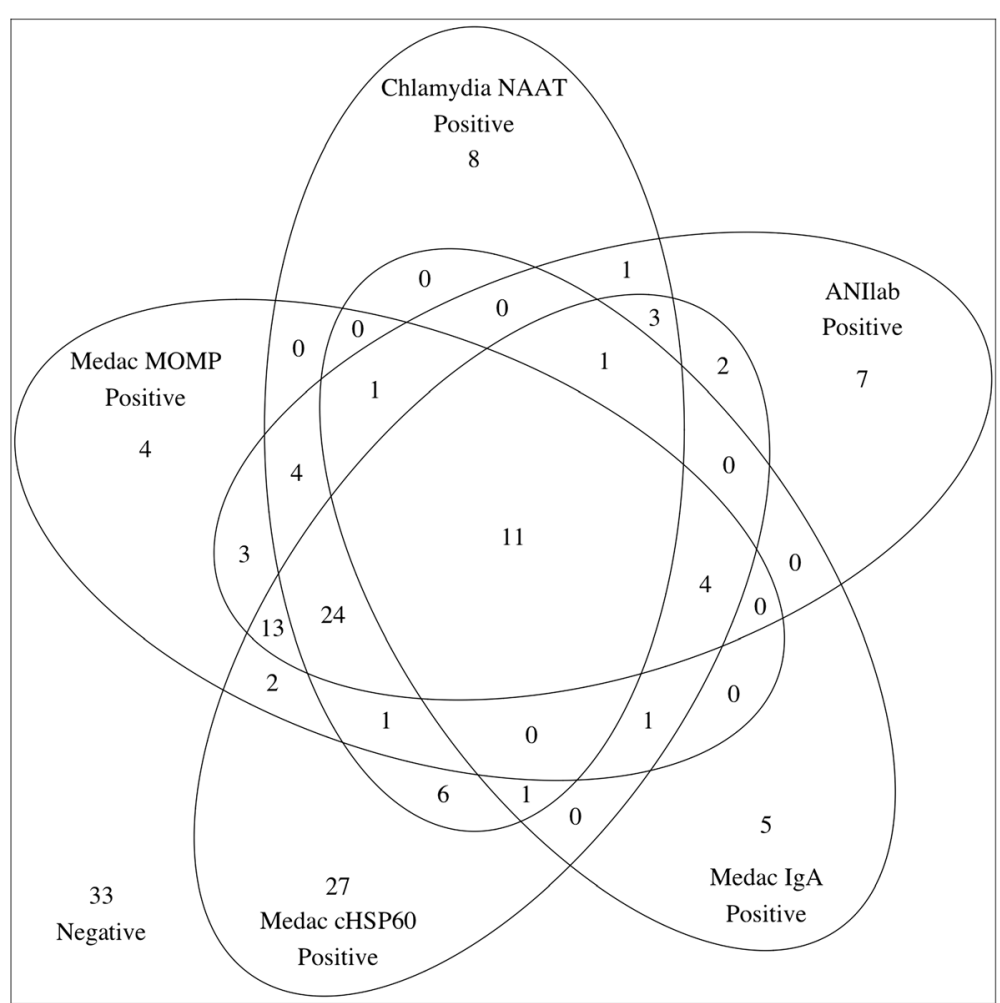

Fig. 2 Venn diagram to demonstrate concordance between serological assays and CT NAAT results. The diagram shows the number of participants positive in each of the assays and those who were positive in more than one assay. The two MOMP assays (MEDAC IgG and ANIlab) and NAAT results showed considerable concordance. The samples that were negative in all assays are also indicated on the figure, only the 162 samples that had a valid result in all of these assays are included in the Venn diagram

assays and NAAT results, particularly between NAAT, MEDAC MOMP, and ANIlab. This supports the notion that these assays are reporting serological responses to CT and are not likely to be a consequence of nonspecific reactivity.

\section{Discussion}

The results of this study imply that up to half (51\% infertile women positive for MEDAC MOMP) of women who are sub-fertile in this population could have CT as a cause or contributing factor. To our knowledge this is one of the highest burdens of CT associated sub-fertility reported to date. This is higher than most studies report, even those conducted in fertility clinics, but is consistent with a fertility clinic study in India that found a similar prevalence [15]. This may be a reflection of the absence of routine screening and treatment for $\mathrm{CT}$ infections in this population.

A possible limitation of our study is that the serological results may be influenced by a higher number of repeat infections given the high prevalence of infection in this population. These repeat infections may lead to higher positives in these assays which use absorbance thresholds that have been designed on clinically defined infertile cohorts, often in settings with a much lower background prevalence. The MEDAC Infertile assay was not significantly associated with sub-fertility in this study. Nevertheless, the high prevalence of cHSP60 antibodies (one of the components of the MEDAC test) could suggest that chronic infections or sequelae are high in this population. Most studies that found a significant association had TFI as the specified measure for infertility [9]. In this population we have limited knowledge of the other fertility factors as this was a village-based survey in the absence of any gynecological investigations that would normally be conducted in a fertility clinic. In addition it is of course possible, considering the sensitivities of obtaining sexual behavior information that some women were mis-classified with respect to subfertility. The amount of sexual activity was of course not the same for each woman, affecting their individual probabilities of becoming pregnant.

The study findings indicated a higher fertility rate in the older ages (although the inclusion criteria were limited to the most reproductive years). The higher fertility in the older women is not that unexpected and is likely because this study is based on sexually active women who were all within the ideal reproductive age, so the 
longer the period of sexual activity the more likely the women are to have conceived. Alternatively, this could be explained by an increased desire of these women (25-29 year olds) to achieve pregnancy leading to increased sexual activity.

It was unexpected to find a significant correlation of sero-positivity to C. pneumoniae with sub-fertility in this population. It is difficult to determine if this is actually serological cross reactivity (or a genuine association). Serology to C. pneumoniae, or the presence of the organism, has been previously found to significantly correlate with various diseases [19-21], but not with subfertility. One possible explanation for this finding could be that the infertile women in this population have tissue lesions or adhesions in the fallopian tube that may form a reservoir for the pathogen and perhaps the immune response to this reserve of $\mathrm{CP}$ may exacerbate the CT pathology that results in development of tubal subfertility. This persistence in the scarring site could explain the high prevalence of CP serology that, whilst significant, is not causal for sub-fertility. Alternatively, this could be a chance result. Firstly, as the prevalence of Chlamydia pneumoniae antibodies is very high (in both fertile and infertile women), statistical analysis tends to lead to an overestimation of the odds ratio. Secondly, the number of participants included in the analysis is relatively low $(\mathrm{n}=233)$.

MEDAC MOMP and MEDAC CP were the only assays that significantly correlated with sub-fertility, suggesting that whilst serology is a much more feasible manner to measure possible chlamydial infertility in the developing world setting the current assays may be confounded by the high prevalence, and only MEDAC MOMP may be suitable.

\section{Conclusions}

The high prevalence of $C$. trachomatis infections in Samoa is likely to be leading to high rates of preventable sub-fertility in this population. The results reported here using serological and epidemiological data collection indicate that CT-associated sub-fertility could be a factor for as much as half of the burden of sub-fertility in sexually active women in this reproductive age range in Samoa.

\section{Ethics approval and consent to participate}

Participants provided informed written consent, completed an interviewer-led questionnaire and provided biological samples. The initial ethical approval was from National University of Samoa, Samoa National Health Service Board approval for the use of the Laboratory and staff, and the Samoa Ministry of Women approved the village based survey, and the Samoan Ministry of Health. Ethical approval was previously reported [19] and Queensland University of Technology Human Research Ethics Committee approval was also obtained (approval number 1100000276).

\section{Consent for publication \\ Not applicable.}

\section{Availability of data and methods}

All data that is not present in the publication will be made available upon request in de-identified format. The questionnaire development and details are previously presented and can be provided upon request.

\section{Abbreviations}

Cl: confidence interval; CT: Chlamydia trachomatis; MEDAC Cpn: MEDAC Chlamydia pneumoniae pELISA; MEDAC MOMP: MEDAC Chlamydia trachomatis pELISA; MEDAC CHSP60: MEDAC C. trachomatis CHSP60 ELISA; MEDAC Infertile: combined results from MEDAC MOMP and MEDAC CHSP6O to predict infertile/chronic sequelae outcomes from C. trachomatis infections as per the manufacturer's recommendations; OR: odds ratio; NAAT: nucleic acid amplification test.

\section{Competing interests}

The authors declare that they have no competing interests.

\section{Authors' contributions}

SM conducted laboratory serology assays. EH, IL, TN, SVAT, ISL, LA, SAT, MMF, and TSS all contributed to recruitment, questionnaire implementation and field work. SM, SSH, MW, EH, AAR, PT, PH, WMH analysed data and contributed to design. All authors had input into manuscript preparation. All authors read and approved the final manuscript.

\section{Acknowledgements}

We would like to thank the participants, village leaders, and various stakeholders in Samoa.

\section{Funding}

The field study was funded by the New Zealand Aid Programme. The serological assay component was funded by a Queensland Government Smart State National and International Research Alliance for research into Chlamydia awarded to P Timms, sub-project leader W Huston.

\section{Author details}

${ }^{1}$ Institute of Health and Biomedical Innovation, Queensland University of Technology, Brisbane, Australia. ${ }^{2}$ Centre for International Health, University of Otago, Dunedin, New Zealand. ${ }^{3}$ National University of Samoa, Apia, Samoa. ${ }^{4}$ National Health Service Laboratory Division, Apia, Samoa. ${ }^{5}$ Samoa Family Health Association, Apia, Samoa. ${ }^{6}$ Centre for Samoan Studies, National University of Samoa, Apia, Samoa. ${ }^{7}$ Samoa National Council of Churches, Apia, Samoa. ${ }^{8}$ Samoa AIDS Foundation, Apia, Samoa. ${ }^{9}$ Victoria University of Wellington, Wellington, New Zealand. ${ }^{10}$ Faculty of Science, Health, Education and Engineering, University of the Sunshine Coast, Maroochydore, Australia.

${ }^{11}$ School of Life Sciences, Faculty of Science, University of Technology Sydney, Broadway, Sydney, NSW, Australia. ${ }^{12}$ School of Life Sciences, University of Technology Sydney, PO BOX 123, Broadway, Sydney, NSW 2007, Australia.

Received: 8 October 2015 Accepted: 13 April 2016

Published online: 21 April 2016

\section{References}

1. Adams EJ, Charlett A, Edmunds WJ, Hughes G. Chlamydia trachomatis in the United Kingdom: a systematic review and analysis of prevalence studies. Sex Transm Infect. 2004;80(5):354-62.

2. Kohli R, Konya WP, Obura T, Stones W, Revathi G. Prevalence of genital Chlamydia infection in urban women of reproductive age, Nairobi, Kenya. BMC Res Notes. 2013;6:44. 
3. Lewis D, Newton DC, Guy RJ, Ali H, Chen MY, Fairley CK, Hocking JS. The prevalence of Chlamydia trachomatis infection in Australia: a systematic review and meta-analysis. Bmc Infect Dis. 2012;12:113.

4. Sullivan EA, Koro S, Tabrizi S, Kaldor J, Poumerol G, Chen S, O'Leary M Garland SM. Prevalence of sexually transmitted diseases and human immunodeficiency virus among women attending prenatal services in Apia, Samoa. Int J Std Aids. 2004;15(2):116-9.

5. Cliffe SJ, Tabrizi S, Sullivan EA, Pacific Islands Second Generation HIVSG. Chlamydia in the Pacific region, the silent epidemic. Sex Transm Dis. 2008; 35(9):801-6.

6. Broeze KA, Opmeer BC, Coppus SF, Van Geloven N, Alves MF, Anestad G, Bhattacharya S, Allan J, Guerra-Infante MF, Den Hartog JE, et al. Chlamydia antibody testing and diagnosing tubal pathology in subfertile women: an individual patient data meta-analysis. Hum Reprod Update. 2011;17(3):301-10.

7. Land JA, Gijsen AP, Kessels AGH, Slobbe MEP, Bruggeman CA. Performance of five serological chlamydia antibody tests in subfertile women. Hum Reprod. 2003;18(12):2621-7.

8. Tiitinen A, Surcel HM, Halttunen M, Birkelund S, Bloigu A, Christiansen G, Koskela P, Morrison SG, Morrison RP, Paavonen J. Chlamydia trachomatis and chlamydial heat shock protein 60-specific antibody and cell-mediated responses predict tubal factor infertility. Hum Reprod. 2006:21(6):1533-8.

9. Witkin SS, Askienazy-Elbhar M, Henry-Suchet J, Belaisch-Allart J, TortGrumbach J, Sarjdine K. Circulating antibodies to a conserved epitope of the Chlamydia trachomatis $60 \mathrm{kDa}$ heat shock protein (hsp60) in infertile couples and its relationship to antibodies to $C$. trachomatis surface antigens and the Escherichia coli and human HSP60. Hum Reprod. 1998;13(5):1175-9.

10. Witkin SS, Linhares IM. Chlamydia trachomatis in subfertile women undergoing uterine instrumentation - An alternative to direct microbial testing or prophylactic antibiotic treatment. Hum Reprod. 2002;17(8):1938-41.

11. Spandorfer SD, Neuer A, LaVerda D, Byrne G, Liu HC, Rosenwaks Z, Witkin SS. Previously undetected Chlamydia trachomatis infection, immunity to heat shock proteins and tubal occlusion in women undergoing in-vitro fertilization. Hum Reprod. 1999;14(1):60-4.

12. Coppus SF, Land JA, Opmeer BC, Steures P, Eijkemans MJ, Hompes PG, Bossuyt PM, van der Veen F, Mol BW, van der Steeg JW. Chlamydia trachomatis lgG seropositivity is associated with lower natural conception rates in ovulatory subfertile women without visible tubal pathology. Hum Reprod. 2011;26(11):3061-7.

13. Coppus SF, Opmeer BC, Logan S, van der Veen F, Bhattacharya S, Mol BW. The predictive value of medical history taking and Chlamydia lgG ELISA antibody testing (CAT) in the selection of subfertile women for diagnostic laparoscopy: a clinical prediction model approach. Hum Reprod. 2007;22(5):1353-8.

14. Keltz MD, Sauerbrun-Cutler MT, Durante MS, Moshier E, Stein DE, Gonzales E. Positive Chlamydia trachomatis serology result in women seeking care for infertility is a negative prognosticator for intrauterine pregnancy. Sex Transm Dis. 2013:40(11):842-5.

15. Malik A, Jain S, Rizvi M, Shukla I, Hakim S. Chlamydia trachomatis infection in women with secondary infertility. Fertil Steril. 2009;91(1):91-5.

16. Muvunyi CM, Dhont N, Verhelst R, Temmerman M, Claeys G, Padalko E. Chlamydia trachomatis infection in fertile and subfertile women in Rwanda: prevalence and diagnostic significance of $\lg G$ and $\lg A$ antibodies testing. Hum Reprod. 2011;26(12):3319-26.

17. Siemer J, Theile O, Larbi Y, Fasching PA, Danso KA, Kreienberg R, Essig A. Chlamydia trachomatis infection as a risk factor for infertility among women in Ghana, West Africa. Am J Trop Med Hyg. 2008;78(2):323-7.

18. Walsh MS, Hope E, Isaia L, Righarts A, Niupulusu T, Temese SV, losefa-Siitia L, Auvaa L, Tapelu SA, Motu MF, et al. Prevalence of Chlamydia trachomatis infection in Samoan women aged 18 to 29 and assessment of possible risk factors: a community-based study. Trans Royal Soc Trop Med Hyg. 2015; 109(4):245-51.

19. Ramirez JA. Isolation of Chlamydia pneumoniae from the coronary artery of a pateient with coronary atherosclerosis. The Chlamydia pneumoniae/ atherosclerosis Study group. Ann Intern Med. 1996;125(12):979-82.

20. Balin BJ, Gerard HC, Arking EJ, Appelt DM, Branigan PJ, Abrams JT, Whittum-Hudson JA, Hudson AP. Identification and localization of Chlamydia pneumoniae in the Alzheimer's brain. Med Microbiol Immunol. 1998;187(1):23-42.

21. Gerard HC, Dreses-Werringloer U, Wildt KS, Deka S, Oszust C, Balin BJ, Frey WH, 2nd, Bordayo EZ, Whittum-Hudson JA, Hudson AP. Chlamydophila (Chlamydia) pneumoniae in the Alzheimer's brain. FEMS Immunol Med Microbiol. 2006;48(3):355-66.
22. Hjelholt A, Christiansen G, Johannesson TG, Ingerslev HJ, Birkelund S. Tubal factor infertility is associated with antibodies against Chlamydia trachomatis heat shock protein 60 but not human HSP60. Hum Reprod. 2011;26:2069-76.

23. van den Broek IVF, Land JA, van Bergen JEAM, Morr'e SA, van der Sande MAB: Chlamydia trachomatis antibody testing in vaginal mucosal material versus blood samples of women attending a fertility clinic and an STI clinic. Obstet Gynecol International 2014, 2014(601932).

24. De Ory F, Guisasola ME, Eiros JM. Detection of Chlamydophila pneumoniae lgG in paired serum samples: comparison of serological techniques in pneumonia cases. APMIS. 2006;114(4):279-84.

\section{Submit your next manuscript to BioMed Central and we will help you at every step:}

- We accept pre-submission inquiries

- Our selector tool helps you to find the most relevant journal

- We provide round the clock customer support

- Convenient online submission

- Thorough peer review

- Inclusion in PubMed and all major indexing services

- Maximum visibility for your research

Submit your manuscript at www.biomedcentral.com/submit

) Biomed Central 